\title{
LIMIT LOAD OF COLD FORMED THIN-WALLED NONSTANDARD CHANNEL BEAMS
}

\author{
Maciej Obst \\ Poznan University of Technology, Faculty of Machines and Transportation, Poznan, Poland \\ e-mail: maciej.obst@put.poznan.pl \\ Marcin Rodak, Piotr Paczos \\ Poznan University of Technology, Institute of Applied Mechanics, Poznań, Poland \\ e-mail: marcin.rodak@put.poznan.pl; piotr.paczos@put.poznan.pl
}

\begin{abstract}
Cold-formed thin-walled beams may lose the stability in different ways. The common buckling modes which have an influence on the failure of the beam are lateral-torsional, local and distortional buckling. The strength of cold-formed members can be calculated with the Effective Width Method which is incorporated in many international and national standards. In this paper, the experimental and theoretical results calculated with the aforementioned method have been compared.
\end{abstract}

Keywords: thin walled beams, limit load, EC3

\section{Introduction}

Different types of loss of stability are distinguished. First one is connected with global beam buckling which is characterized by invariability of the shape of beam cross-section and long length of the half-wave of the buckling. When the wall thickness of the beam is relatively small in comparison with the width of the individual walls, then the local buckling of the beam may exist. The length of the half-wave of the buckling is small and it is comparable with the wall widths which are buckled. The beam may lose the stability in a distortional mode which was characterized by Hancock (1997) for channel sections as a rotation of the flange with its deflection in relation to the axis of connection between the flange and web. The length of the half-wave of the buckling for this type of mode of stability loss is equal to the intermediate values for the above mentioned cases. The strength of the beam can be limited by the occurrence of the above mentioned modes of stability loss. In this work, the results of experimental investigations which have been conducted in the Laboratory of the Strength of Materials at the Poznan University of Technology are applied - these ones are discussed by Pacos $(2012,2013$, 2014). Similar investigations were conducted by Pastor and Roure (2008) who considered two loading conditions. Silvestre and Camotim (2010) described the mechanics of distortion in thin-walled open sections. Magnucka-Blandzi et al. (2012) proposed formulas which made it possible to determine the critical load of double box flange beams. They increased the strength and stability of those structural members but complicated their analysis because there were different possible buckling modes: local, distorsional (rotation of a stiffened flange at a flange/web function) or global, e.g. flexular torsional buckling. The results of experimental investigations of thin-walled beams were presented by Magnucki et al. (2010), and Magnucka-Blandzi (2011) and SudhirSastry et al. (2015).

Practical calculations of the strength of the thin-walled beams which can locally lose the stability are based on the Effective Width Method (EWM). It is applied in many international and domestic standards, e.g. PN-EN 1993-1-3 (2008), PN-EN 1993-1-5 (2008) and AISI S100-2007 
(2007). The effective width method has been elaborated as an approximate model of strength of long and slender plates $(L \gg b)$ (Fig. 1a). Next it has been adopted to calculations of thin-walled beams. In the case of plates which are freely supported on four edges and uniformly compressed on two short edges, the distribution of normal stresses is not quite uniform after exceeding the critical compressive stresses (Fig. 1b). This state is approximated by giving the effective width of the plate beff where the uniform distribution of stresses exists, and for the other width it is assumed that the stress values are equal t zero. Moreover

$$
\sigma_{2} A_{\text {eff }}=\sigma_{1} A
$$

where $A=t b$ and $A_{\text {eff }}=t b_{\text {eff }}$.
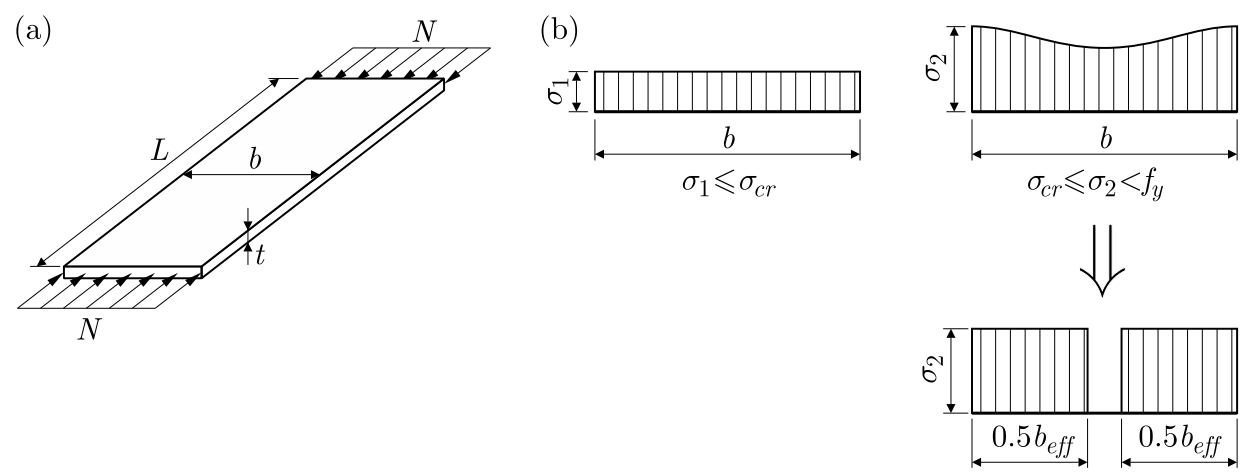

Fig. 1. (a) Plate freely supported on edges and compressed by a uniformly distributed force which is applied to the edges $b$, (b) distribution of normal stresses in the plate

Direct methods are other methods which are commonly applied. The most known method is the Direct Strength Method (DSM) proposed by Schafer, applied in US standards (AISI S-100-2007, 2007) and presented in many other works, e.g. Shafer (2008), Batista (2009, 2010) described the Effective Section Method (ESM).

The authors of this paper have compared strength of cold-formed thin-walled beams calculated on the basis of PN-EN 1993-1-3 (2008) with the results of the experimental investigations (Paczos, 2012). During the determination of the theoretical limiting moment the local buckling of the beam has been taken into consideration only. Freely supported and pure bending beams for the measuring length $L=400,500,600 \mathrm{~mm}$ (Fig. 2) have been investigated. Channel section beams with double and single boxes have been analysed (Fig. 3).

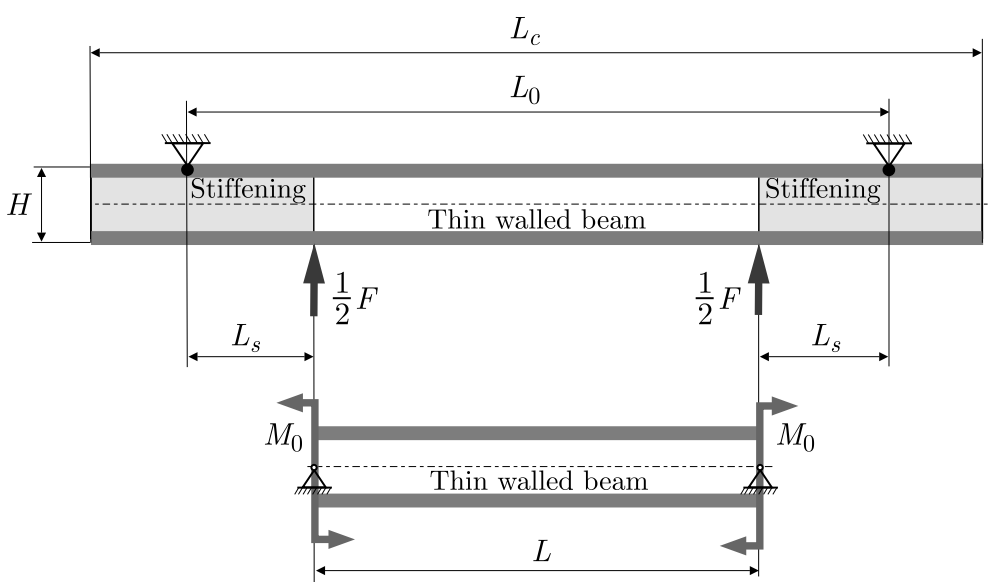

Fig. 2. Loading scheme

The presented subject is the development of researches that have been conducted in the Division of Strength of Materials and Structures of Poznan University of Technology. 


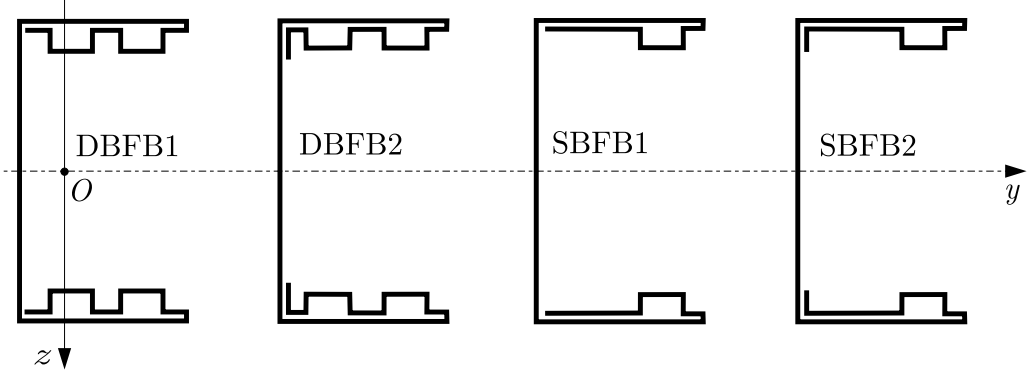

Fig. 3. Channel section beams with double boxes and with single boxes

\section{Calculations}

The limit value of the moment for the beam can be calculated on the basis of the following formula

$$
M_{g r}=f_{y} W_{e f f}
$$

where $f_{y}$ is the yield stress of the material, $W_{\text {eff }}$ - effective section modulus for bending calculated for the local buckling of the beam walls, so the distortional mode of buckling has been omitted. The calculations have been done iteratively, because after every calculation of the effective width of the beam walls the centre of cross-section has been changed (the distribution of normal stresses is also changed in the cross-section).

The effective width of the beam wall is equal to

$$
b_{\text {eff }}=\rho b_{c}+b_{t}
$$

where $\rho$ is the reduction ratio, $b_{c}$ - beam width where compressive stresses exist (positive), $b_{t}$ - beam width where tensile stresses exist (negative).

The calculation has been based on the assumption that cross section can be yielded only by local buckling. Therefore, it is assumed that all walls do not have any additional stiffening (see PN-EN 1993-1-3, 2008, point 5.5.2) and next the authors proceeded according to the procedure described in standard (PN-EN 1993-1-5, 2008). The load capacity of shape of the cross-section of the beam has also been determined on the assumption of elastic stress distribution in the cross-section of the beam.

Solution algorithm according to EC3

1. Calculate the bending strength indicator of cross-section $W_{y}$ with the assumption that width of the supporting walls is equal to their imaginary width. Substitute $W_{y, \text { eff }}^{(i)}=W_{y}$, where $i=1$.

2. Substitute $i:=i+1$.

3. For each investigated wall (beam web, upper and lower flange wall, bend) calculate elastic critical stress (plate elastic buckling)

$$
\sigma_{c r}=k_{\sigma} \frac{\pi^{2} E}{12\left(1-\nu^{2}\right)}\left(\frac{t}{b_{p}}\right)^{2}
$$

where values $k_{\sigma}$ can be found in at (PN-EN 1993-1-5, 2008, Table 4.1, 4.2), and $E$ is Young's modulus, $\nu$ - Poisson's ratio, $t$ - wall thickness, $b_{p}$ - imaginary width of wall. 
4. Slenderness plate and reduced slenderness plate for each of investigated walls are calculated with the following formulas

$$
\bar{\lambda}_{p}=\sqrt{\frac{f_{y}}{\sigma_{c r}}} \quad \bar{\lambda}_{p, r e d}=\bar{\lambda}_{p} \sqrt{\frac{\sigma_{1}}{f_{y}}}
$$

where $f_{y}$ is yield strength, $\sigma_{1}$ - maximal stress in the wall (compressive stress).

5. Reduction coefficient $\rho$ can be calculated by the following formulas (PN-EN 1993-1-5, 2008, E.1)

— for cantilevered walls

$$
\rho=\frac{1-0.188 / \lambda_{p, r e d}}{\bar{\lambda}_{p, \text { red }}}+0.18 \frac{\bar{\lambda}_{p}-\bar{\lambda}_{p, \text { red }}}{\bar{\lambda}_{p}-0.6} \quad \text { but } \quad \rho \leqslant 1
$$

— for span walls

$$
\rho=\frac{1-0.053(3+\psi) / \bar{\lambda}_{p, r e d}}{\bar{\lambda}_{p, \text { red }}}+0.18 \frac{\bar{\lambda}_{p}-\bar{\lambda}_{p, r e d}}{\bar{\lambda}_{p}-0.6} \quad \text { but } \quad \rho \leqslant 1
$$

where $\bar{\lambda}_{p}=\sqrt{f_{y} / \sigma_{c r}}$ - plate slenderness, $\bar{\lambda}_{p, \text { red }}=\bar{\lambda}_{p} \sqrt{\sigma_{1} / f_{y}}$ - reduced plate slenderness, $\psi=\sigma_{2} / \sigma_{1}, \sigma_{1}$ - maximum compressive stresses on one edge of the wall, $\sigma_{2}$ - stresses on opposite edge of the wall, $\sigma_{c r}$ - critical elastic stresses for the wall.

6. Calculate effective width ((PN-EN 1993-1-5, 2008, Table 4.1, 4.2) for each investigated walls.

7. Calculate the strength indicator $W_{y, \text { eff }}^{(i)}$.

8. If $\left(W_{y, \text { eff }}^{(i)}-W_{y, \text { eff }}^{(i-1)}\right) / W_{y, \text { eff }}^{(i)}<\varepsilon$ then $M_{g r}=W_{y, \text { eff }}^{(i)} f_{y}$ and finish. Otherwise start calculations from point 2 .

The iterative procedure is rapidly convergent. To determine final values, few iterations are sufficient depending on the measure accuracy accepted for calculations (in this paper $\varepsilon=0.001$ has been accepted). A flow chart of the procedure is presented in Fig. 4.

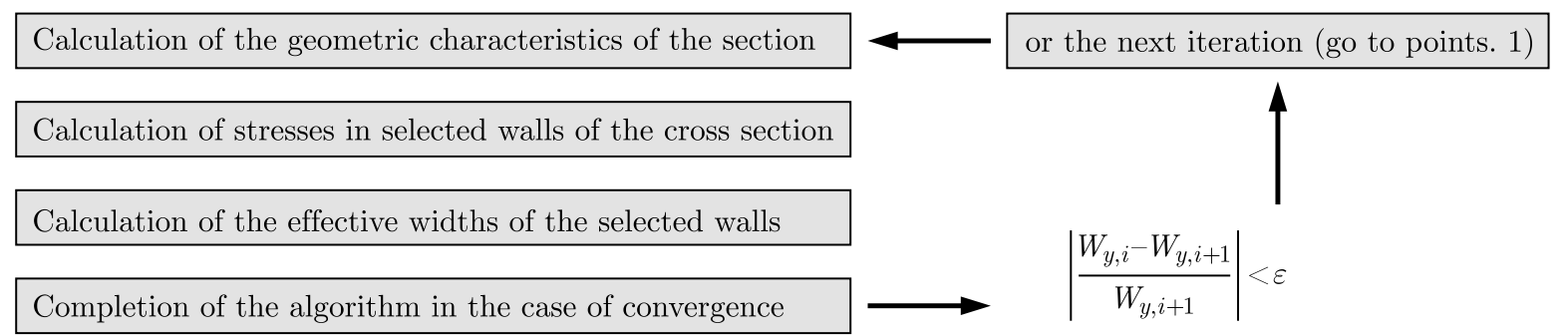

Fig. 4. Simplified block diagram of the effective cross-section calculation algorithm for pure bending

The above presented formulas can be found in standard PN-EN 1993-1-5 (2008). Figure 5 presents the examined sections and walls which are analysed for the local buckling.

The main reason for experimental investigations is the search for the optimal (strongest) shape of the cross-section of the beam. The beams are made of the same material and have the same length and wall-thickness. Two kinds of beams with double-box and single-box flange have been investigated: $L=400,500$ and $600 \mathrm{~mm}$. 


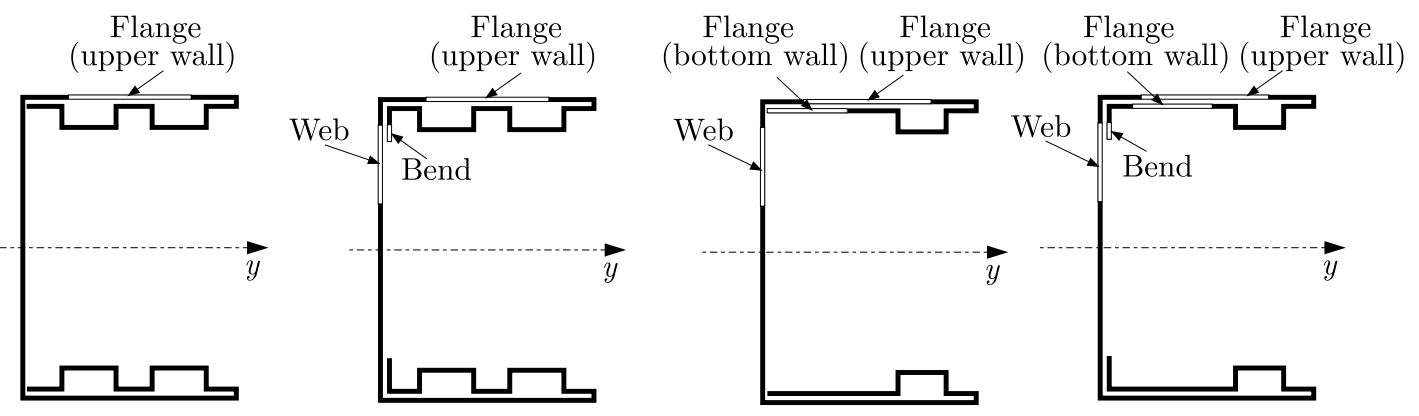

Fig. 5. Effective sections DBFB1, DBFB2 and SBFB1, SBFB2

\section{Experimental investigations}

The examined beams were produced by "Pruszyński Sp. z o.o.", Sokołów, Polska and made of steel: $E=1.81 \cdot 10^{5} \mathrm{MPa}, v=0.3$ and $f_{y}=329 \mathrm{MPa}$. The tests have been performed with testing machine ZWICK Z100 having the range up to $100 \mathrm{kN}$. a four point bending test has been conducted for the beams where pure bending has been obtained for the measuring length $L$ (Fig. 6).

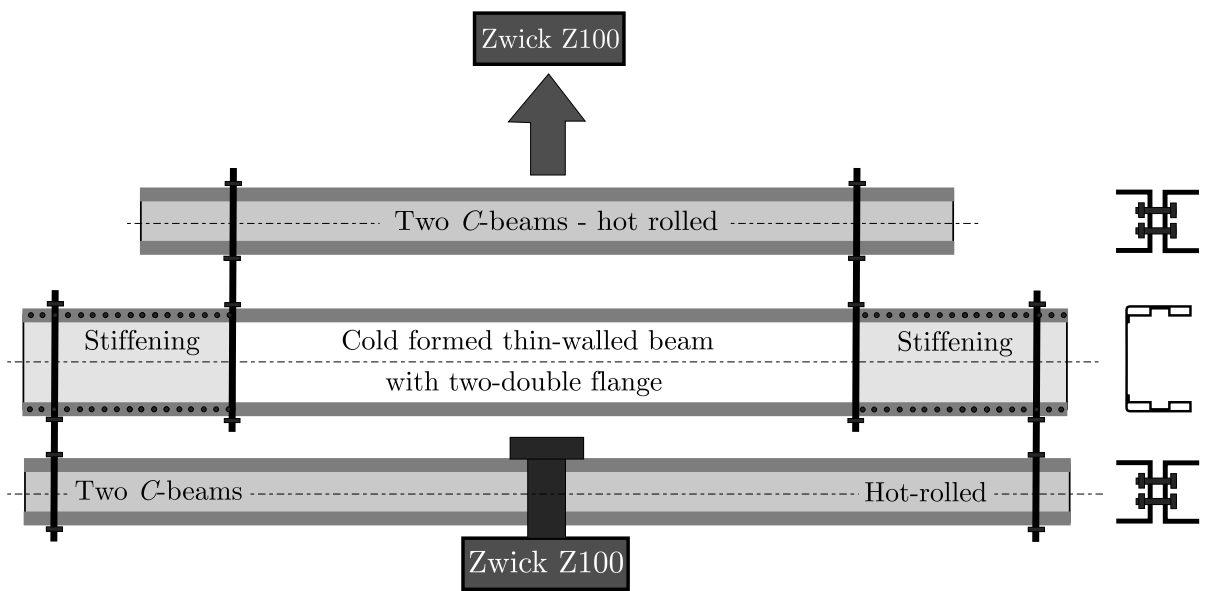

Fig. 6. Scheme of the test stand

The following equipment has been used for experimental investigations: strain gauge bridge SPAIDER, the deflection sensor $15 \mathrm{~mm}$ (WA15) HOTINGER, foil strain gauges HBM type $6 / 120 \mathrm{LY} 11$, gauge factor 2 . They have been loaded with two moments (pure bending). Some results are presented in tables and drawings (Fig. 7 and Table 1-4). The test stand and the beam is presented in Fig. 7 .

Relations between the deflection of the lower flange and the load-force within the full range of the load (maximum force) are shown in Fig. 8.

The growth of displacements of cold-formed thin-walled beams under increasing load causes local buckling that may also interact with global buckling. It is a result of the low load capacity of thin-walled beams that depends on dimensions of the beam, boundary conditions (support), load or shape of the cross-section.

The investigated beams have been made by cold-form technology of sheet steel bending using numerical CNC machines. During experimental research of beams there was no considerable aberration of the defined lateral and lengthwise dimensions. Apart from the measurement of deflection of the middle part of beam, strains have also been measured in five measuring points of the tested cross-section. Two measuring points have been placed on the beam web and 

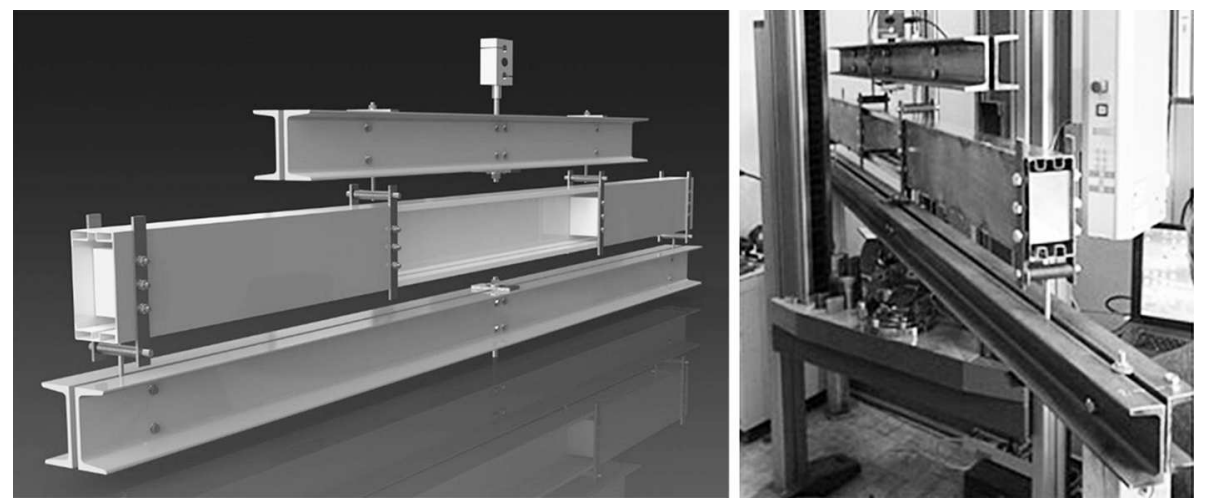

Fig. 7. Test stand (simulation of pure bending)
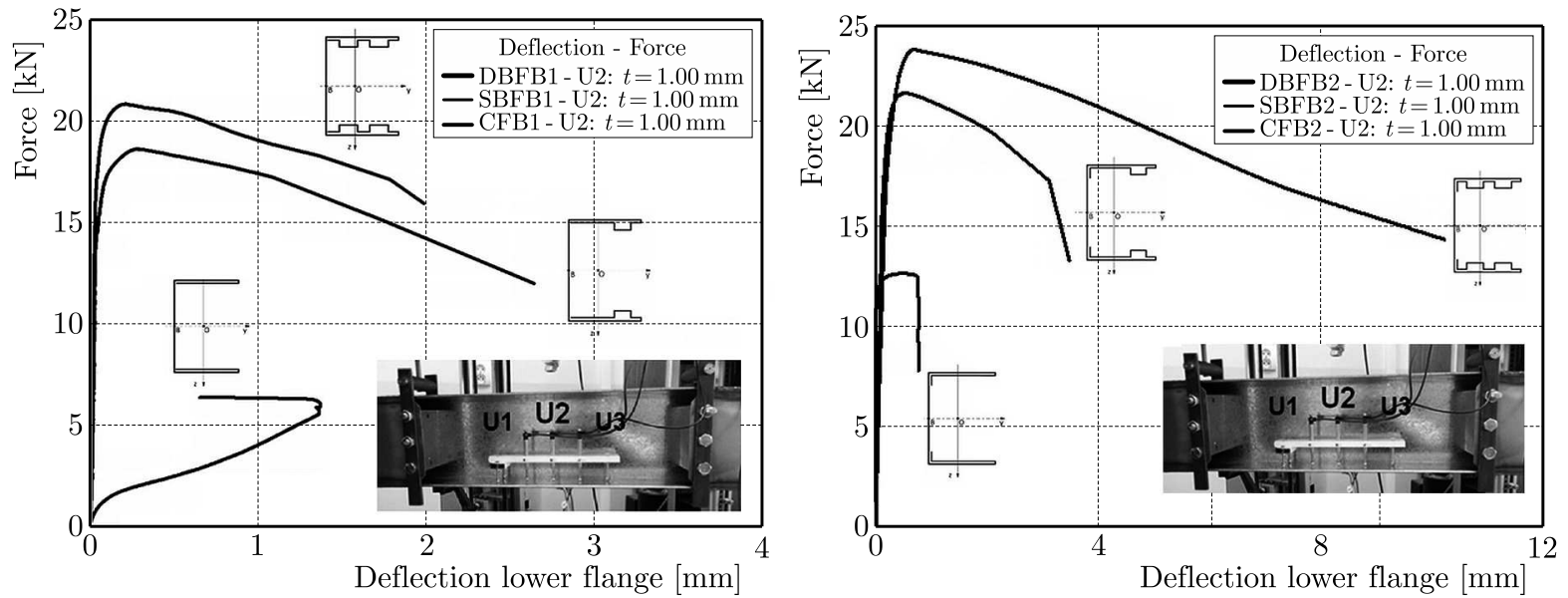

Fig. 8. Experimental relationship between forces and deflection of the lower flange for thickness $t=1.00 \mathrm{~mm}$ (beams: DBFB1, SBFB1, DBFB2, SBFB2)

three measuring points have been placed on on the press lower beam flange. On the basis of the obtained strain results and beam sheet metal material properties, stress values have been calculated. During the experimental research of beams, local buckling shapes were observed and maximum values of forces were measured which corresponded to the limit load of the beam. The participation of distortional buckling was negligible and for different cross-sections of beams it is value was in the range from $2 \%$ up to $4 \%$ of the maximal force.

\section{Comparison of the results}

This Section presents a comparison of strength of the beams obtained by experimental investigations and the procedure described in Standard PN-EN 1993-1-5 (2008). The dimensions of cross-sections are the following (Fig. 9): $H=160.0 \mathrm{~mm}$ - height of the beam (external dimension), $b=80.0 \mathrm{~mm}$ - width of the flange, $c=0.0 \mathrm{~mm}, 20.0 \mathrm{~mm}$ - length of the reinforcement, $d=18.0 \mathrm{~mm}$ - height of the flange, $e=14.0 \mathrm{~mm}, f=18.0 \mathrm{~mm}, 30.0 \mathrm{~mm}, 40.0 \mathrm{~mm}, t=1.00 \mathrm{~mm}$ and $1.25 \mathrm{~mm}$ - wall thickness.

Tables 1 and 2 show the comparison of the results for beams with double boxes, with and without reinforcement, correspondingly.

Tables 3 and 4 show the comparison of the results for beams with single boxes, with and without reinforcement, correspondingly. 

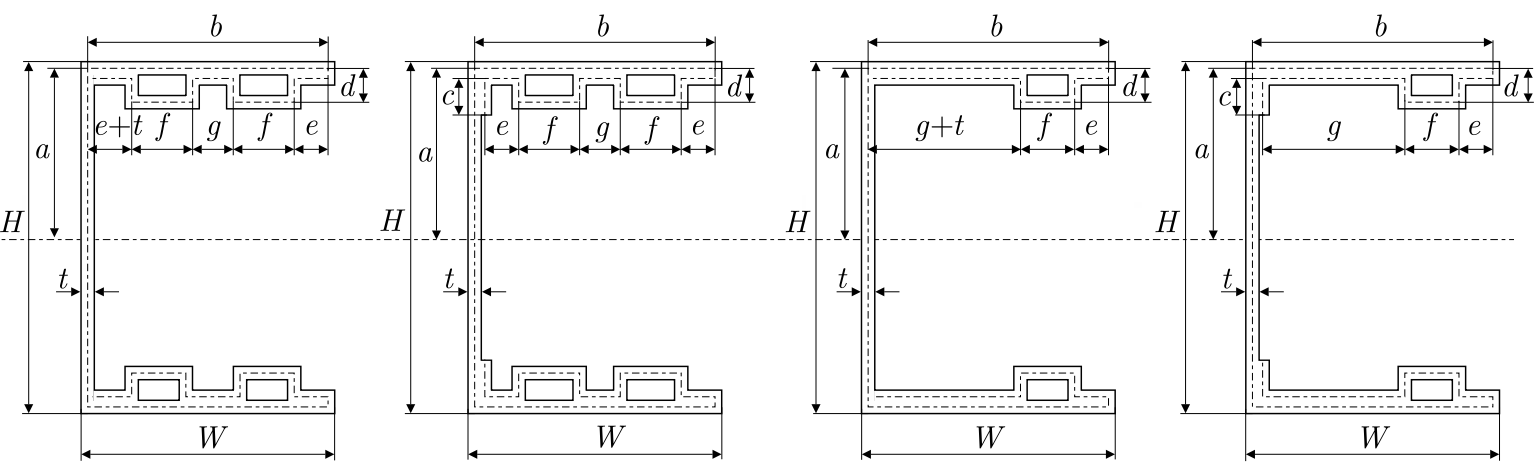

Fig. 9. Channel section beams with double boxes (without and with bend) and with single boxes (without and with bend)

Table 1. Values of limiting loads - DBFB1

\begin{tabular}{|c|c|c|c|c|c|}
\hline $\begin{array}{c}t \\
{[\mathrm{~mm}]}\end{array}$ & $\begin{array}{c}M_{g r}^{(E C 3)} \\
{[\mathrm{kNm}]}\end{array}$ & $\begin{array}{c}L \\
{[\mathrm{~mm}]}\end{array}$ & $\begin{array}{c}M_{g r}^{(e x p)} \\
{[\mathrm{kN}]}\end{array}$ & $\begin{array}{c}M_{g r, s r}^{(e x p)} \\
{[\mathrm{kN}]}\end{array}$ & $\begin{array}{c}\mathcal{A} \\
{[\%]}\end{array}$ \\
\hline \multirow{3}{*}{1.00} & \multirow{3}{*}{9.03} & 4400 & - & \multirow{3}{*}{7.79} & $\overline{-}$ \\
\hline & & 500 & 7.79 & & 19.0 \\
\hline & & 600 & - & & - \\
\hline \multirow{3}{*}{1.25} & \multirow{3}{*}{12.05} & 400 & - & \multirow{3}{*}{10.49} & - \\
\hline & & 500 & 10.49 & & $\overline{14.8}$ \\
\hline & & 600 & - & & - \\
\hline
\end{tabular}

Table 2. Values of limiting loads - DBFB2

\begin{tabular}{|c|c|c|c|c|c|}
\hline $\begin{array}{c}t \\
{[\mathrm{~mm}]}\end{array}$ & $\begin{array}{c}M_{g r}^{(E C 3)} \\
{[\mathrm{kNm}]}\end{array}$ & $\begin{array}{c}L \\
{[\mathrm{~mm}]}\end{array}$ & $\begin{array}{c}M_{g r}^{(e x p)} \\
{[\mathrm{kN}]}\end{array}$ & $\begin{array}{c}M_{g r, s r}^{(e x p)} \\
{[\mathrm{kN}]}\end{array}$ & $\begin{array}{c}\mathcal{A} \\
{[\%]}\end{array}$ \\
\hline \multirow{3}{*}{1.00} & \multirow{3}{*}{9.70} & 400 & 8.85 & \multirow{3}{*}{8.60} & $\overline{9.6}$ \\
\hline & & 500 & 8.78 & & 10.5 \\
\hline & & 600 & 8.18 & & 18.5 \\
\hline \multirow{3}{*}{1.25} & \multirow{3}{*}{12.87} & 400 & 12.74 & \multirow{3}{*}{12.15} & 1.0 \\
\hline & & 500 & 12.07 & & 6.6 \\
\hline & & 600 & 11.63 & & 10.6 \\
\hline
\end{tabular}

\section{Conclusions}

Strength of the beams with double boxes (DBFB1, DBFB2) is higher than strength of the beams with single boxes (SBFB1, SBFB2). This result has been expected. The similar situation exists for the beams with and without reinforcement. The beams with reinforcement (DBFB2, SBFB2)have higher values of the limiting moment than the beams without reinforcement (DBFB1, SBFB2).

The analysis of the obtained results allows one to state that the strength values obtained with Standard PN-EN 1993-1-5 (2008) are higher than the experimental values. Moreover, this difference grows with an increase in the measuring length of the beam. The reason for this fact is the interaction of two forms of buckling, i.e. local and distortional one, and an increase in the percentage contribution of the second form in conjunction with an increase in the measuring length of the beam. 
Table 3. Values of limiting loads - SBFB1

\begin{tabular}{|c|c|c|c|c|c|}
\hline $\begin{array}{c}\text { Dimensions } \\
{[\mathrm{mm}]}\end{array}$ & $\begin{array}{c}M_{g r}^{(E C 3)} \\
{[\mathrm{kNm}]}\end{array}$ & $\begin{array}{c}L \\
{[\mathrm{~mm}]}\end{array}$ & $\begin{array}{c}M_{g r}^{(e x p)} \\
{[\mathrm{kN}]}\end{array}$ & $\begin{array}{c}M_{g r, s r}^{(e x p)} \\
{[\mathrm{kN}]}\end{array}$ & $\begin{array}{c}\mathcal{A} \\
{[\%]}\end{array}$ \\
\hline \multirow{3}{*}{$\begin{aligned} t & =1.00 \\
f & =30.00\end{aligned}$} & \multirow{3}{*}{6.83} & 2400 & $\overline{c 6.91}$ & \multirow{3}{*}{6.66} & -1.2 \\
\hline & & 500 & 6.77 & & 0.9 \\
\hline & & 600 & 6.31 & & 0.8 \\
\hline \multirow{3}{*}{$\begin{array}{c}t=1.00 \\
f=40.00\end{array}$} & \multirow{3}{*}{7.11} & 400 & 6.81 & \multirow{3}{*}{6.81} & 4.5 \\
\hline & & 500 & 6.84 & & 3.9 \\
\hline & & 600 & 6.79 & & 4.8 \\
\hline \multirow{3}{*}{$\begin{array}{c}t=1.25 \\
f=30.00\end{array}$} & \multirow{3}{*}{9.42} & 400 & - & \multirow{3}{*}{-} & - \\
\hline & & 500 & - & & - \\
\hline & & 600 & - & & - \\
\hline \multirow{3}{*}{$\begin{aligned} t & =1.25 \\
f & =40.00\end{aligned}$} & \multirow{3}{*}{9.75} & 400 & - & \multirow{3}{*}{-} & - \\
\hline & & 500 & - & & - \\
\hline & & 600 & - & & - \\
\hline
\end{tabular}

Table 4. Values of limiting loads - SBFB2

\begin{tabular}{|c|c|c|c|c|c|}
\hline $\begin{array}{c}\text { Dimensions } \\
{[\mathrm{mm}]} \\
\end{array}$ & $\begin{array}{c}M_{g r}^{(E C 3)} \\
{[\mathrm{kNm}]} \\
\end{array}$ & $\begin{array}{c}L \\
{[\mathrm{~mm}]} \\
\end{array}$ & $\begin{array}{c}M_{g r}^{(e x p)} \\
{[\mathrm{kN}]} \\
\end{array}$ & $\begin{array}{c}M_{g r, s r}^{(e x p)} \\
{[\mathrm{kN}]} \\
\end{array}$ & $\begin{array}{c}\mathcal{A} \\
{[\%]} \\
\end{array}$ \\
\hline \multirow{3}{*}{$\begin{array}{c}t=1.00 \\
f=30.00\end{array}$} & \multirow{3}{*}{8.30} & 400 & 7.96 & \multirow{3}{*}{7.89} & 4.2 \\
\hline & & 500 & 7.89 & & 5.1 \\
\hline & & 600 & 7.82 & & 6.1 \\
\hline \multirow{3}{*}{$\begin{array}{c}t=1.00 \\
f=40.00\end{array}$} & \multirow{3}{*}{8.24} & 400 & - & \multirow{3}{*}{-} & - \\
\hline & & 500 & - & & - \\
\hline & & 600 & - & & - \\
\hline \multirow{3}{*}{$\begin{array}{c}t=1.25 \\
f=30.00\end{array}$} & \multirow{3}{*}{11.31} & 400 & 11.47 & \multirow{3}{*}{10.93} & -1.4 \\
\hline & & 500 & 10.98 & & 3.0 \\
\hline & & 600 & 10.34 & & 9.4 \\
\hline \multirow{3}{*}{$\begin{array}{c}t=1.25 \\
f=40.00\end{array}$} & \multirow{3}{*}{11.09} & 400 & - & \multirow{3}{*}{-} & - \\
\hline & & 500 & - & & - \\
\hline & & 600 & - & & - \\
\hline
\end{tabular}

Moreover, this difference is higher for cross-sections with two boxes (DBFB1, DBFB2) than with single boxes (SBFB1, SBFB2). This results from the fact that the cross-sections with single boxes are more sensitive to local bucking, and this type of buckling has a higher percentage contribution in beam destruction than distortional buckling. Theoretical results are based on the following assumption: the beam loses local stability only - so, a better agreement between the results exists for the cross-sections with single boxes SBFB1 and SBFB2.

In the case of the cross-section with single boxes SBFB1, one can notice that the strength for $f=30 \mathrm{~mm}$ is higher than for $f=40 \mathrm{~mm}$, and this means that $W_{\text {eff }, f=30}<W_{\text {eff, } f=40}$, but it is known that $W_{y, f=30}>W_{y, f=40}$ where $W_{\text {eff }, f=x}$ and $W_{y, f=x}$ are the bending indicators, respectively, the effective one and the indicator in the elastic range for $f=x$. This situation is caused by the following fact: during the beam flange compression the span wall has higher length for the case of $f=30 \mathrm{~mm}$ than $f=40 \mathrm{~mm}$, and the effective widths of these span walls for both cross-sections have similar values - this leads to the above mentioned relationships.

To sum up, one should take into account the distortional buckling of the beam during calculations of the beam strength. 


\section{Acknowledgement}

The presented research results executed within project No. 02/21/DSPB/3464 have been funded by the Ministry of Science and Higher Education.

\section{References}

1. AISI S100-2007, 2007, North American specification for the design of cold-formed steel members, American Iron and Steel Institute

2. Batista E.M., 2009, Local-global buckling interaction procedures for design of cold-formed columns: effective width and direct method integrated approach, Thin-Walled Structures, 47, 12181231

3. Batista E.M., 2010, Effective section method: a general direct method for design of steel coldformed members under local-global buckling interaction, Thin-Walled Structures, 48, 345-356

4. HANCOCK G.J., 1997, Design for distortional buckling of flexural members, Thin-Walled Structures, 27, 3-12

5. Magnucka-Blandzi E., 2011, Effective shaping of cold-formed thin-walled channel beams with double-box flanges in pure bending, Thin-Walled Structures, 49, 121-128

6. Magnucka-Blandzi E., Paczos P., Wasilewicz P., 2012, Buckling study of thin-walled channel beams with double-box flanges in pure bending, International Journal for Experimental Mechanics, 48, 317-325

7. Magnucki K., Paczos P., Kasprzak J., 2010, Elastic buckling of cold-formed thin-walled channel beams with drop flanges, ASCE: Journal of Structural Engineering, 136, 7, 886-896

8. Paczos P., 2012, Stability and limit load of thin-walled cold-formed channel beams, Proceedings of Stabilty of Structures XIII-th Symposium, Zakopane 2012, Kowal-Michalska K., Mania R.J. (Edit.), 539-546

9. Paczos P., 2013, Experimental and numerical (FSM) investigations of thin-walled beams with double-box flanges, Journal of Theoretical and Applied Mechanics, 51, 2, 497-504

10. Paczos P., 2014, Experimental investigations of thin-walled C-beams with nonstandard flanges, Journal of Constructional Steel Research, 93, 77-87

11. Pastor M.M., Roure F., 2008, Open cross-section beams under pure bending. I Experimental investigations, Thin-Walled Structures, 46, 476-483

12. PN-EN 1993-1-3, 2008, Eurokod 3, Projektowanie konstrukcji stalowych. Część 1-3: Reguły ogólne. Reguły uzupełniające dla konstrukcji z kształtowników i blach profilowanych na zimno, PKN, Warszawa 2008

13. PN-EN 1993-1-5, 2008, Eurokod 3, Projektowanie konstrukcji stalowych. Część 1-5, Blachownice. PKN, Warszawa 2008

14. Schafer B.W., 2008, Review: the Direct Strength Method of cold-formed steel member design, Journal of Constructional Steel Research, 64, 766-778

15. Silvestre N., Camotim D., 2010, On the mechanics of distortion in thin-walled open sections, Thin-Walled Structures, 48, 469-481

16. SudhirSastry Y.B., Krishna Y., Pattabhi Budarapu R., 2015, Parametric studies on buckling of thin walled channel beams, Computational Materials Science, 96, 416-424 